\title{
Instructional Scaffolding in the Teaching of English Writing Based on the Online Writing Platform
}

\author{
Li LI ${ }^{1, a, *}$ \\ ${ }^{1}$ School of Foreign Languages, Shanghai University of Political Science and Law, \\ Shanghai, China \\ alily2211@126.com
}

Keywords: Instructional scaffolding, Online writing platform, Teaching of English writing.

\begin{abstract}
Writing is an indispensable part of English learning. However, the present situation of English writing teaching is far from satisfaction. This paper aims at studying online writing teaching based on instructional scaffolding and analyzing how to make full use of various scaffoldings in the teaching of EFL writing so as to enhance student's interest in writing and improve their writing proficiency.
\end{abstract}

\section{Introduction}

Instructional scaffolding is defined as a guidance or support from teachers, instructors or other knowledgeable persons that facilitate students to achieve their goals in learning [1]. Many studies have been carried out on instructional scaffolding in the foreign language teaching, but few are about online writing teaching. This study mainly focuses on the question whether instructional scaffolding can be applied to online writing teaching to enhance student's interest in writing and improve their writing proficiency based on the online writing platform.

\section{Instructional Scaffolding}

Instructional scaffolding, a teaching approach, mainly stems from the work of Wood, Bruner and Ross in 1976 [2]. It relates to Social Constructivism Theory pioneered by Lev Vygotsky and his popular concept known as the Zone of Proximal Development (ZPD). ZPD is an area of learning that occurs when a person is assisted by a teacher or peer with a skill set higher than that of the subject [3]. That is, this theory of ZPD essentially stated that a gap exists between what a person can do and learn on his or her own, and what can be learned or done with the assistance of another person who is more experienced or knowledgeable.

The ZPD concept is seen as a scaffold, a structure of "support points" for performing an action [4]. This refers to the help or guidance received from an adult or more competent peer to permit the child to work within the ZPD [5]. Although Vygotsky himself never mentioned the term, scaffolding was first developed by Jerome Bruner, David Wood, and Gail Ross, while applying Vygotsky's concept of ZPD to various educational contexts [6]. The term 'scaffolding' was borrowed from construction field (scaffold is a temporary structure that supports building) [7]. In education, scaffolding was used to vividly describe a teaching approach that teachers instruct students in the early stages of learning, and gradually lessen their supports as the students gain mastery [8]. This reduces difficulty of complex learning and at the same time, let the students focus on constructing knowledge and higher-order demands like thinking critically [9]. In the whole process of the teaching, students are the focus while teachers mainly guide them to master, construct and internalize what 
they have learned so that students are able to extend their potentials to the full play and their cognitive skills build around that leaned concept.

Various investigations, using different approaches and research frameworks have proved collaborative learning to be effective in many kinds of settings and contexts [10]. Teachers should assign tasks that students cannot do on their own, but which they can do with assistance; they should provide just enough assistance so that students learn to complete the tasks independently and then provide an environment that enables students to do harder tasks than would otherwise be possible [11].

\section{English Writing on the Online Writing Platform}

English writing teaching is the important component of English teaching, but it has been widely acknowledged that English writing teaching is a rather tough and challenging task. To a certain degree, it is considered as a burden for teachers to respond student essays. Every teacher of English has a large number of students. If they assign frequent assignments, it might be rather time-consuming to offer individual feedback to student essays. Consequently, parts of teachers are unwilling to assign more essays, and though some do, they only assess part of student assays, namely half or a third of all the students. What's more, while assessing these essays, most of teachers merely underline the mistakes made in the essays and then grade or score them, which demotivates students' interest in writing and minimizes the effective feedback to student essays. In effect, feedback is an essential aspect of the writing process. Students need to receive feedback from the teacher in order to increase their writing quality. As far as the students are concerned, some of them can't put stress on the feedback that their teacher provides. Though part of them revises the essays accordingly, they seldom put in a lot of time and energy into the content of essays. Instead, they emphasize the form more, which can't be helpful for them to improve their writing quality and increase their writing ability. In the process of English writing, a number of students can't complete their writing actively. After writing their essays, they don't read any more and ignore the very important step of revision. So the only reader and evaluator is their teacher. Teachers and students can't interact with one another. Nor can't students themselves. Therefore, students don't have much knowledge of how to improve the writing quality by revision. Students' initiative can't be displayed in the English writing [12].

As the growing use of both computers and the Internet in English language teaching, such online communication methods as online discussion, online writing, QQ, forums, SKYPEE, are employed as an instructional strategy and put into practical teaching by part of teachers in China, which contributes to the reform carried out in English language teaching. In particular, a variety of Automated Essay Scoring (AES) systems are used to help teachers to assess student essays and students to improve their writing proficiency to a great extent. It was apparent that more effective input will promote student's writing proficiency with the application of AES into English writing teaching.

The scaffolding is no longer implemented via face-to-face instruction that literally exists between a teacher and students in a classroom. Currently, the form of instructions that emerges between teachers and students is mediated through the online settings. Based on the online writing platform, writing teaching, with the guidance of Instructional Scaffolding, is able to make full use of teaching recourses and gradually shifts its focus from writing results to writing process, which is of much help to develop students' habit of collaborative learning and improve their ability of 
autonomous learning. Besides, while students are studying on their own, teachers can provide them with different types of scaffolding at different stages to assist them complete their writing. Therefore, in the whole teaching process, teachers should consider different types of scaffolding students need in their online writing and provide them with such scaffolding timely so as to develop their ability of writing and construct knowledge, which helps them bridge the ZPD and have better development of cognitive skills

As to online writing teaching based on the online writing platform, the application of IS mainly centers on the current key points of the teaching and help students construct a conceptual frame of knowledge so as to promote their better understanding of what they have learned and what they are going to learn.

So, teachers have to make good preparation for their class, fully master what they are going to present in class and fragmentize the complicate content of the courses ahead of class so that students are able to have a good understanding and knowledge construction from the easy to the difficult. Then in the teaching design, it is essential for teachers to design some questions which aim to enhance their ability of thinking for themselves and encourage them to participate in the discussion actively and learn to cooperate in the learning, which benefits students in bettering themselves in the conceptual frame. The main purpose is to shift the task of managing the learning form teachers to students themselves and help students complete the task and internalize the learning process.

\section{Instructional Scaffolding in the Online Writing Teaching on the Online Writing Platform}

In the whole process, teachers are constantly changing their roles and growing into those who guide and promote students to construct concepts actively and help them complete their task. In general, instructional scaffolding model (ISM) is composed of the following five steps.

\section{Building a Scaffold in the Class}

According to ZPD concerning the present instructional theme and main task, ISM inspires to construct the conceptual frame. First of all, teachers assist students construct knowledge and internalize the prior knowledge which is of much use to cultivate their ability to put their language into practice. At this time, it is necessary for teachers to build an instructive scaffold for students in class. Note that the smaller, specific learning objectives for the instructional unit are clearly defined, so teachers have to make clear the theme they are going to write about and give students clear explanation of writing requirements, relevant knowledge and writing skills. At this stage, teachers help students understand the basic rules and essence reflected in what they are learning in class and the inherent relation of what they have learned and what they are learning so as to help them construct a meaningful knowledge building.

\section{Creating Real-world Settings}

At this stage, it is very essential for teachers to supply suggestive and guiding scaffolding for students without delay in different forms such as raising questions, brainstorming, etc. In this case, students are led to a real-world context with certain questions which can arouse their interest, inspire their thought and promote their communication with each other. Students are guided to write all the possible ideas in their own mind and improve their ability of finding more writing materials, which can help students avoid the phenomenon that they don't have something to write about, 
and urge them to make great efforts to solve the problem. In effect, with the help of teachers' support, prior knowledge and relevant experience having existed in their mind are able to adapt to new knowledge they just learned. In the adaptation, students' cognitive structure will be enriched and gradually complete their knowledge construction.

\section{Independent Exploring}

Set aside enough time for students to think and discuss, and students are sure to have some ideas of the theme. At this time, with the guidance of teachers, students must give full play to their subjective initiative and then make an outline independently with given time. This stage aims to give student rare opportunities to exercise their independence and autonomy, so teachers must allow them to do independently and go on climbing on their own within the frame. Once completing their task, they can submit their writing online and correct their mistakes and polish their writing according to the auto feedback given by the online writing platform. The self-correcting process is virtually a period when students examine themselves, introspect and affirm themselves. Therefore, it is very necessary for teachers to instruct students to make full use of the plentiful online resources and corpus on the online writing platform and effectively increase their input, which helps students assimilate new knowledge by means of the old knowledge and build a scaffold for the next stage.

\section{Collaborative Learning}

At this stage, collaborative learning can be achieved by group discussion in class and online peer assessment. In the group discussion, teachers have to provide prompt support for the students in the forms of question-and-answer and heuristic questions. In fact, scaffold can be constructed not only by teachers but by their classmates. They can help each other in the writing process. Online writing platform makes it possible for students to cooperate with each other because it offers ideal technical support and implementation platform. With such an advantage, multilayer and all-around collaborative learning model will be gradually constructed, which centers on the students. Of course, teachers have to provide reasonable and specific standards for peer assessment so that they can assess their writings and their classmates' effectively, and reduce blindness and randomness in assessing their and others' writings. Online peer assessment is done anonymously, which can avoid a problem of face and also arouse students' interest in English writing. Students usually take their images in their classmates' eyes into consideration, so they have to take it seriously when assessing and correcting their own writings. They naturally keep in mind what standards a good writing must meet and have a good understanding of specific requirements, which benefits students a lot. In addition, in the process of assessing the writing, they learn from their classmates and in the meantime prevent themselves from making similar mistakes. When they learn to appreciate other's writings, they can improve their own sensitivity of realizing possible mistakes, learn how to look at the problem from different perspectives, cultivate their critical and creative thinking and develop a habit of autonomous learning. After peer assessment, students are required again to correct their own writing, produce the final edition and then submit it online to teachers to assess. 


\section{Summarization and Assessment}

The writing assessment system based on the online writing platform is virtually a multi-layer and multi-aspect system, including assessment of online writing platform, students' self-assessment, peer assessment and teachers' assessment. In the whole process of writing, these types of assessment are employed to assess students' writings. Online instantaneous assessment arouses students' interest and motivation in writing effectively. Thus it is unavoidable for students to have more chances to write, which can broaden their horizon and open their mind. Undoubtedly, teachers' feedback is of great importance and has its instructive meanings for students. But it should be pointed out that the assessment teachers give should be mostly positive, which is seen as incentive scaffold, which helps students build up their confidence in writing and improve their cognitive skills. In the whole process of writing, every step is beneficial for students to construct their knowledge.

\section{Conclusion}

According to IS, students' learning is seen as a process of gradually internalizing what they have learned. With the guidance of ISM, online writing teaching considers students as the constructors of learning, which is bound to promote the transformation of writing teaching from traditionally result-oriented approach to process-oriented approach. In order to give a full play to their initiative and promote their internalization of acquired knowledge, teachers have to provide students with different types of instructions promptly at different stages of learning so as to help them bridge a cognitive gap, guide them to improve their cognitive skills and construct the sense of knowledge. In the long run, students' writing will be in the virtuous circle, which facilitates students to achieve their goal in learning and contributes to improving their writing proficiency in the end.

\section{References}

[1] N.F. Jumaat, Z. Tasir, Instructional Scaffolding in Online Learning Environment: A Meta-analysis, Proceedings of the 2014 International Conference on Teaching and Learning in Computing and Engineering, pp.74-77, 2014.

[2] D. Wood, J. Bruner, G. Ross, The Role of Tutoring in Problem Solving, Journal of Child Psychology \& Psychiatry and Applied Disciplines, vol. 17, no.2, pp. 89-102, 1976.

[3] W.M. Roth, Zone of Proximal Development. Journal of Russian \& East European Psychology, vol. 47, no. 6, pp. 48-69, 2009.

[4] C. Quintana, B. J. Reiser, E. A. Davis, J. Krajcik, E. Fretz, R. G. Duncan, et. al, A Scaffolding Design Framework for Software to Support Science Enquiry, Journal of the Learning Sciences, vol. 3,no. 3, pp. 337-386, 2004.

[5] M. Tiantong, S. Teemuangsai, The Four Scaffolding Modules for Collaborative Problem-based Learning Through the Computer Network on Moodle LMS for the Computer Programming Course, International Education Studies, vol. 6, no. 5, pp. 47-55, 2013. 
[6] M. Zhang, C. Quintana, Scaffolding Strategies for Supporting Middle School Students' Online Inquiry Processes, Computers \& Education, vol. 58, no. 1, pp. 181-196, 2012.

[7] J. van De Pol, M. Volman, J. Beishuizen, Scaffolding in Teacher-student Interaction: A Decade of Research, Educational Psychology Review, vol. 22, no. 3, pp. 271-296, 2010.

[8] A. S. Palinscar, The Role of Dialogue in Providing Scaffolded Instruction, Educational Psychologist, vol. 21, no. 1 \& 2, pp. 73-98,1986.

[9] J. Way, L. Rowe, The Role of Scaffolding in the Design of Multimedia Learning Object, Paper presented at the 11th International Congress on Mathematical Education, Mexico: July. 6 - July 13, 2008.

[10]A. Carr, R. Luckin, R, K. Avramides, N. Yuill, Scaffolding Metacognitive Processes in the Ecolab: Help-seeking and Achievement Goal Orientation, Proceedings of the 15th International Conference on Artificial Intelligence in Education, pp. 432-434, 2011.

[11]H. Huang, C. Wu, N. Chen, The Effectiveness of Using Procedural Scaffolding in a Paper-plus-smartphone Collaborative Learning Context, Computers \& Education, vol. 59, no. 2, pp. 250-259, 2012.

[12]L.Li, Experimental Study on the Validity of AES Systems in the College EFL Classroom, Proceedings of the 2014 International Conference on Teaching and Computational Science. 2014. 